\title{
Chronic Distal Biceps Rupture in Military Personnel
}

\author{
Alexander Habashy ${ }^{1 *}$, Damon Greene ${ }^{2}$, Tara Saxena ${ }^{3}$, Scott Montgomery ${ }^{1}$ and Misty Suri ${ }^{1}$ \\ ${ }^{1}$ Ochsner Clinic Foundation, USA \\ ${ }^{2}$ Shore Orthopedic University Associates, USA \\ ${ }^{3}$ University of Queensland, Australia \\ Submission: February 13, 2018; Published: March 08, 2018 \\ *Corresponding author: Alexander Habashy, Department of Orthopedics, Ochsner Clinic Foundation, 1514 Jefferson Hwy, New Orleans, LA 70121, \\ USA, Email: alexander.habashy@ochsner.org
}

\begin{abstract}
The treatment of distal biceps tendon rupture is dependent on a variety of factors, including time from injury to presentation as well as desired level of activity. High demand patients as well as patients presenting within days of rupture typically undergo operative treatment, whereas those with a delayed presentation and/or elderly patients are typically treated conservatively. We present a case of a 37-year-old male who sustained bilateral distal biceps tendon ruptures during military training. He was initially treated conservatively, but was referred to us several months post-injury due to persistent pain and reduced strength bilaterally. His desire to return to active military duty posed an additional unique challenge. He underwent a staged, bilateral distal biceps reconstruction with Achilles allograft due to extensive tendon scarring and myostatic contracture. Postoperatively, the patient had reduced pain, improved motion and markedly improved supination and flexion strength bilaterally. In this paper, we present a review of the literature, challenges unique to chronic distal biceps rupture, as well as novel surgical techniques that aided in our success.
\end{abstract}

Keywords: Chronic biceps rupture; Distal biceps tendon reconstruction; Achilles allograft

\section{Introduction}

Distal biceps tendon ruptures occur in 1.2 per 100,000 people per year. A majority of these injuries occur in the dominant arm of men in their fifth decade of life, with an increased incidence in smokers, anabolic steroid users and weightlifters [1-3]. The mechanism of injury is an eccentric load with the elbow in fixed flexion [4,5]. Treatment options include conservative versus surgical management. Conservative management is reserved for older, less active patients, as these patients will experience reduced strength in supination, flexion, and grip [4,5]. Using Cybex $^{\mathrm{TM}}$ testing, Baker \& Bierwagen [6] found that nonoperative treatment resulted in a $47 \%$ decrease in supination endurance and a $21 \%$ decrease in supination strength when compared to the non-injured extremity. In the operatively treated group, results showed an increase in supination strength of $13 \%$ as well as a $32 \%$ increase in supination endurance.

Acute surgical treatment is the recommended course of action, typically within weeks of biceps tendon rupture. There are many methods described to repair a biceps tendon rupture. The techniques described include reattaching the distal biceps tendon to the radial tuberosity, or non-anatomically by anchoring to the brachialis, through either a one or two incision approach [7,8]. Chronic ruptures pose a surgical challenge, however, as the biceps tendon becomes retracted and scarred. In these cases, patients often require the use of a graft; with an Achilles tendon allograft or hamstrings autograft being common graft choices [9] There is a higher rate of complications in patients undergoing chronic distal biceps reconstruction, including lateral antebrachial cutaneous nerve paresthesias, radial sensory nerve paresthesia, posterior interosseous nerve injury, heterotopic ossification as well as re-rupture [10].

\section{Case Report}

We present a case of 37-year-old right hand dominant male, active duty military personnel, who suffered bilateral distal bicep ruptures 3 years prior to presentation to our clinic. The injury occurred while lifting a $400 \mathrm{lb}$ barrel in his military training. The patient was initially treated conservatively with therapy. He presented to our clinic unsatisfied with the resultant decrease in strength as well as pain. He reported a subjective $50 \%$ decrease in supination and flexion strength. His main concern was being able to pass a fitness test, which would allow him to return to active duty. On exam, he had a palpable defect bilaterally in the antecubital fossa with a positive hook test bilaterally. He had $4 / 5$ strength with supination, and elbow flexion bilaterally. An MRI was performed and revealed chronic distal biceps ruptures with retraction of the myotendinous junction roughly $11 \mathrm{~cm}$ proximal to the radial tuberosity bilaterally.

Conservative and operative treatments were explained in great detail to the patient. With his goal being to return to active military duty, he elected to undergo bilateral distal biceps 


\section{Orthopedics and Rheumatology Open Access Journal}

reconstructions with allograft augmentation. We elected to perform the surgery in a staged manner, undergoing operative reconstruction of the left non-dominant arm first.

\section{Surgical Technique}

A preoperative interscalene block was performed in preoperative holding. He was placed under general anesthesia in the supine position with a hand table placed under his operative extremity. After the left upper extremity was prepped and draped in a sterile fashion, a sterile tourniquet was then placed on his upper left arm and inflated to $250 \mathrm{mmhg}$. A single incision technique was chosen. Using sharp dissection, a lazy-S shaped incision was made over the medial aspect of the antecubital fossa. Our incision began roughly $2 \mathrm{~cm}$ distal to the elbow crease, at the level of the radial tuberosity, and extended proximally and ulnarly about 6-8 $\mathrm{cm}$ above the elbow crease. The lateral antebrachial cutaneous nerve was identified, mobilized and protected. Blunt dissection was used, as there was a large amount of scar tissue. The distal biceps tendon was identified, approximately $8 \mathrm{~cm}$ proximal to its insertion. The undersurface of the distal biceps was freed from the surrounding soft tissues and the neurovascular bundle was protected and retracted medially. The remainder of the scar tissue was carefully resected. The stump of the distal biceps was debrided and cleaned. At this stage, the elbow was flexed to 45 degrees and a trial was performed to reapproximate the stump of the distal biceps tendon to the radial tuberosity.

We elected to use an Achilles allograft to perform the reconstruction portion of the procedure. The bone block was removed from the allograft and the distal stump of the Achilles was contoured to accommodate a $7 \mathrm{~mm}$ tunnel. Fiber-loop was then whipstitched to the distal Achilles stump to pass the graft through the tunnel. A $7 \mathrm{~mm}$ reamer was then used to drill bicortically through the anatomic insertion point at the radial tuberosity. The distal graft was then shuttled through the tunnel using an endobutton to anchor the graft on the dorsal aspect of the tuberosity. Fluoroscopy was then used to ensure accurate positioning of the distal anchor.

Using a bump, the arm was then placed at a resting position of 45 degrees of flexion. The tourniquet was then deflated to allow for appropriate tensioning of the graft. We found that the excursion of the native biceps tendon increased 3-4 cm when the tourniquet was removed. A slit was made in the proximal aspect of the graft to allow for the muscle belly to be pulled through using Allis clamps. This maneuver allowed for the biceps to be appropriately tensioned as well as proper placement of the graft. After appropriate tensioning, a series of interrupted figure-ofeight sutures using \#2 Fiber Wire were then used to repair the central part of the allograft directly to the muscle belly itself. Additional \#2 Fiber Wire figure of 8 sutures were then used medially and laterally to repair the muscle belly to the edges of the graft for additional fixation. The elbow was then taken through a range of motion to ensure that the graft was at the appropriate tension. The wound was then irrigated and closed in a standard fashion. A splint was then placed at 90 degrees of flexion and neutral rotation.

\section{Results}

Two months after our patient's index surgery, he underwent allograft reconstruction of his right distal biceps in a replicated manner. Our patient encountered no major complications during his post-operative course. He did have signs and symptoms consistent with cubital tunnel syndrome in his right upper extremity, which has since improved without surgical intervention. His post-operative protocol included strict immobilization for 2 weeks, followed by gradual eccentric extension protocol. He began aggressive dynamic physical therapy at 6 weeks. His pre-operative Mayo Elbow Performance Score (MEPS) was calculated to be 45 , which put him in the "Poor" category. At 5 months post-op, his DASH score was 7.5 and his MEPS score was 100 bilaterally. At the 9-month postoperative mark, his range of motion was 0-130 degrees, with full pronation and supination strength bilaterally. He is currently 12 months postoperative on the left side and 10 months on the right, and is cleared to lift up to 35 pounds, as well as perform band-assisted pull-ups.

\section{Discussion}

Chronic distal biceps ruptures pose a challenging treatment dilemma as the tendon will retract, lose elasticity and become atrophied, making direct repair more difficult [11]. Traditionally, surgeons have opted to use allograft for chronic distal biceps reconstruction. The fear is that primary end-to-end repair would require excessive intra-operative flexion of the elbow, which would result in decreased extension post-operatively as well as an increased risk of rupture. Morrey et al. [12] tested this theory in recent literature. They performed a retrospective case control study comparing patients undergoing primary repair at 60 degrees or more of flexion versus patients requiring less than 30 degrees of flexion. They found most patients regained functional extension in both groups, with one case of re-rupture in the high flexion group. Nowadays, the need for graft augmentation is usually based on cases where there is extreme retraction of the proximal stump or when primary repair requires flexion of the elbow to greater than 90 degrees [13].

Several retrospective studies have been performed in an effort to evaluate outcomes of chronic distal bicep reconstruction. All studies, however, have low numbers of patients as well as a variety of techniques and graft choices [11,14-17]. Results of these studies did show excellent outcomes with restoration of strength and endurance in most cases. Wiley and colleagues [18] compared the results of seven patients undergoing chronic biceps reconstruction with semitendinosus allograft with seven patients undergoing nonoperative treatment. They found that the surgical group had full return of flexion and supination strength, while the nonoperative group had a residual $20 \%$ decrease in strength. 
Our patient's desire to return to active military duty added an extra level of complexity, as there is a scarcity of literature regarding surgical techniques of chronic biceps rupture in a high demand population. Using a combination of previously described surgical methods as well as some novel techniques; we were able to give our patient the best chance for a successful outcome. One of the technical pearls that we learned from this case is that use of the tourniquet grossly changes that amount of excursion that the native biceps tendon will have. Failure to recognize this effect will cause the graft tendon complex to be inappropriately tensioned if the tourniquet is left inflated during the attachment of the graft. Similarly, we feel that the graft should be tensioned at 45 degrees. If the graft is tensioned at too much flexion, there will be decreased excursion of the tendon and resulting failure of the repair, with loss of patient satisfaction.

\section{Conflict of Interest}

The authors have no conflict of interest to report.

\section{References}

1. D’Alessandro DF, Shields CL, Tibone JE, Chandler RW (1993) Repair of distal biceps tendon ruptures in athletes. Am J Sports Med 21(1): 114-119.

2. Davis WM, Yassine Z (1956) An etiological factor in tear of the distal tendon of the biceps brachii; report of two cases. J Bone Joint Surg Am 38-A(6): 1365-1368.

3. Visuri T, Lindholm H (1994) Bilateral distal biceps tendon avulsions with use of anabolic steroids. Med Sci Sports Exerc 26(8): 941-944.

4. Safran MR, Graha, SM (2002) Distal biceps tendon rupture: incidence, demographics, and the effect of smoking. Clin Orthop Relat Res 404: 275-283.

5. Ward JP, Shreve MC, Youm T, Strauss EJ (2014) Ruptures of the distal biceps tendon. Bulletin of the Hospital for Joint Diseases 72(1): 110119

6. Baker BE, Bierwagen D (1985) Rupture of the distal tendon of the biceps brachii. Operative versus non-operative treatment. J Bone Joint Surg Am 67(3): 414-417.

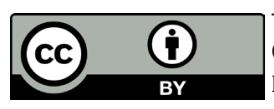

This work is licensed under Creative Commons Attribution 4.0 License

DOI: $10.19080 /$ OROAJ.2018.11.555801
7. Dillon MT, King JC (2013) Treatment of chronic biceps tendon ruptures. Hand 8(4): 401-409.

8. Giacalone F, Dutto E, Ferrero M, Bertolini M, Sard A, et al. (2015) Treatment of distal biceps tendon rupture: why, when, how? Analysis of literature and our experience. Musculoskelet Surg 99(1): S67-S73.

9. Phadnis J, Flannery 0, Watts AC (2016) Distal biceps reconstruction using an Achilles tendon allograft, transosseous Endobutton, and Pulvertaft weave with tendon wrap technique for retracted, irreparable distal biceps ruptures. J Shoulder Elbow Surg 25(6): 1013-1019.

10. Cain RA, Nydick JA, Stein MI (2012) Complications Following Distal Biceps Repair. J Hand Surg Am 37(10): 2112-2117.

11. Darlis NA, Sotereanos DG (2006) Distal biceps tendon reconstruction in chronic ruptures. J Shoulder Elbow Surg 15(5): 614-619.

12. Morrey ME, Abdel MP, Sanchez-Sotelo J, Morrey BF (2014) Primary repair of retracted distal biceps tendon ruptures in extreme flexion. J Shoulder Elbow Surg 23(5): 679-685.

13. Sutton KM, Dodds SD, Ahmad CS, Sethi PM (2010) Surgical treatment of distal biceps rupture. J Am Acad Orthop Surg 18(3): 139-148.

14. Vastamaki M, Vastamaki H (2008) A simple grafting method to repair irreparable distal biceps tendon. Clin Orthop Relat Res 466(10): 24752481.

15. Sanchez-Sotelo J, Morrey BF, Adams RA, O Driscoll SW (2002) Reconstruction of chronic ruptures of the distal biceps tendon with use of an achilles tendon allograft. J Bone Joint Surg Am 84-A(6): 9991005.

16. Levy HJ, Mashoof AA, Morgan D (2000) Repair of chronic ruptures of the distal biceps tendon using flexor carpi radialis tendon graft. Am J Sports Med 28(4): 538-540.

17. Hallam P, Bain GI (2004) Repair of chronic distal biceps tendon ruptures using autologous hamstring graft and the Endobutton. J Shoulder Elbow Surg 13(6): 648-651.

18. Wiley WB, Noble JS, Dulaney TD, Bell RH, Noble DD, et al. (2006) Late reconstruction of chronic distal biceps tendon ruptures with a semitendinosus autograft technique. J Shoulder Elbow Surg 15(4): $440-444$.

\section{Your next submission with Juniper Publishers will reach you the below assets}

- Quality Editorial service

- Swift Peer Review

- Reprints availability

- E-prints Service

- Manuscript Podcast for convenient understanding

- Global attainment for your research

- Manuscript accessibility in different formats

( Pdf, E-pub, Full Text, Audio)

- Unceasing customer service

Track the below URL for one-step submission https://juniperpublishers.com/online-submission.php 